American Journal of Pharmacology and Toxicology 6 (2): 49-54, 2011

ISSN 1557-4962

(C) 2011 Science Publications

\title{
Effect of Niacin on Hyperleptinemia and $O b$ Gene mRNA Over-Expression in Adipose Tissue of Dexamethasone Treated Rats
}

\author{
${ }^{1}$ Tahoora Shomali, ${ }^{2}$ Mahnaz Taherianfard, ${ }^{1}$ Mehdi Fazeli and ${ }^{2}$ Niloofar Safaei \\ ${ }^{1}$ Division of Pharmacology and Toxicology, \\ ${ }^{2}$ Division of Physiology, \\ Department of Basic Sciences, \\ School of Veterinary Medicine, Shiraz University, Shiraz, Iran
}

\begin{abstract}
Problem statement: Glucocorticoid-induced ob gene over-expression and resulted hyperleptinemia may lead to adverse consequences especially on cardiovascular system; therefore, the present study was conducted to evaluate the effects of niacin on hyperleptinemia and ob gene overexpression due to dexamethasone administration in rats. Approach: Twenty four adult male rats divided randomly into four equal groups: 1- normal saline (control), 2- dexamathasone $0.125 \mathrm{mg} \mathrm{kg}^{-1}$ day $^{-1}$, I.M. 3dexamathasone $0.125 \mathrm{mg} \mathrm{kg}^{-1}$ day $^{-1}$, I.M. + niacin $200 \mathrm{mg} \mathrm{kg}^{-1}$ day $^{-1}$, by oral gavages and 4-niacin 200 $\mathrm{mg} \mathrm{kg}^{-1} \mathrm{day}^{-1}$, by oral gavages. After two weeks, blood samples were collected from all animals and leptin level assayed in harvested sera by ELISA method. Moreover, inguinal adipose tissue was excised to be examined for ob gene expression using quantitative real-time PCR. Results: Dexamethasone treatment (group 2) increased serum leptin along with its mRNA expression more than 3 folds as compared to control $(\mathrm{p}<0.001$ and $\mathrm{p}=0.001$ respectively). Although leptin level in rats treated with dexamethasone+niacin was $17.8 \%$ lower than group 2 ; however this decrease was not significant $(p>0.05)$. Concomitant administration of niacin with dexamethasone significantly decreased leptin gene mRNA expression compared to dexamethasone treated rats $(\mathrm{p}<0.001)$ and even reversed it to the control level $(\mathrm{p}>0.05)$. Niacin alone (group 4) had no effect on serum leptin concentration as well as leptin gene expression in comparison with control group ( $>0.05$ ). Conclusion: Niacin slightly ameliorates hyperleptinemia and reverses $o b$ gene mRNA over-expression in adipose tissue of dexamethasone treated rats.
\end{abstract}

Key words: Glucocorticoids, leptin disturbances, niacin, body weight, adipose tissue, leptin gene, tissue fat, cholesterol diet, ameliorates hyperleptinemia, Peroxisome ProliferatorActivated Receptor $\gamma(\operatorname{PPAR} \gamma)$

\section{INTRODUCTION}

Niacin (nicotinic acid or vitamin $\mathrm{B}_{3}$ ) is one of the most prescribed medications for the treatment of dyslipidemia and coronary heart disease (Crouse, 1996). Although the discovery of anti hyperlipidemic effects of niacin dates back to 1955; this agent has recently attracted renewed interest. First, because it is the most potent drug available for the increasing HDL-c and secondly, because it has been found to induce regression of atherosclerosis in patients with coronary heart disease (Taylor et al., 2004; Kamanna and Kashyap, 2008).

A major site of action of niacin is adipose tissue; where it reduces the release of free fatty acids by inhibiting lipolysis (Westphal et al., 2007).

Leptin, the $16 \mathrm{kDa}$ product of $o b$ gene, is most notably released by adipose tissue and bridges the peripheral adipose tissue to the central nervous system for the control of appetite and energy expenditure (Friedman, 2002). It has been demonstrated that elevated serum leptin levels or hyperleptinemia, lowers arterial distensibility (Singhal et al., 2002) and enhances the calcification of vascular cells and

Corresponding Author: Tahoora Shomali, Division of Pharmacology and Toxicology, Department of Basic Sciences, School of Veterinary Medicine, Shiraz University, Shiraz, P.O. Box: 71345-1731, Iran Tel: +98 (711) 6138907 Fax: +98 (711) 2286940 
potentiates the pro thrombotic platelet aggregation (Konstantinides et al., 2001; Parhami et al., 2001). Besides, this hormone stimulates proliferation and migration of vascular smooth muscle cells which may lead to the formation and development of vascular lesions (Oda et al., 2001). Hyperleptinemia correlates with insulin resistance and other markers of metabolic syndrome including obesity, hyperlipidemia and hypertension independent of total adiposity and may be an independent risk factor for the development of cardio-vascular disease (Ren, 2004). Moreover, leptin can possibly increase endothelin-1 expression and elevated levels of this peptide have been reported in numerous disease states including congestive heart failure, obesity and diabetes (Sakr, 2010). Research suggests that adipose tissue-derived hormones, adiponectin and/or leptin, may be playing an important role in energy homeostasis and insulin resistance in the HIV-associated metabolic syndrome (Khalsa et al., 2006).

Although widely prescribed for their potent anti inflammatory and immuno suppressive properties, glucocorticoids (e.g., dexamethasone) may cause major side effects (Patel et al., 2011; Bubanovic et al., 2005). Several previous studies have clearly demonstrated that glucocorticoid administration could be associated with hyperleptinemia and increased $o b$ gene expression in vitro as well as in laboratory animals and humans (Murakami et al., 1995; De Vos et al., 1995; Slieker et al., 1996; Reul et al., 1997; Papaspyrou-Rao et al., 1997; Bradley and Cheatham, 1999; Caldefie-Chezet et al., 2001; Lee et al., 2007; Jahng et al., 2008).

Effects of niacin on serum leptin levels and $o b$ gene expression have been dissimilar according to the different experimental procedures used. While WangFisher et al. (2002) observed that niacin and its derivative, acipimox, stimulate leptin release from adipocytes isolated from normal as well as diabetic rats Yang et al. (2008) clearly demonstrated that niacin can reduce serum level and mRNA expression of leptin in adipose tissue of dietary-induced hypercholesterolemic rabbits. To our knowledge, no previous study has addressed the effect of niacin on glucocorticoid-induced hyperleptinemia and increased leptin mRNA in adipose tissue; this provides the rationale for accomplishing the present study. Dexamethasone was selected because of its high potency on glucocorticoid receptors with insignificant mineralocorticoid receptor activity (Patel et al., 2011).

\section{MATERIALS AND METHODS}

Animals and experimental design: Twenty four adult male Sprague-Dawley rats with a mean body weight of
$230 \mathrm{~g}$ were purchased from animal house of Shiraz Medical University, Shiraz, Iran. Rats were acclimatized for one week before the beginning of the experiment to the ambient conditions (temperature about $23^{\circ} \mathrm{C}$ and a $12 \mathrm{~h} / 12 \mathrm{~h}$, light/dark cycle). Then the animals were randomly allocated into four equal groups (six animals each) and treated for two weeks as follows: group one (control) received normal saline daily by intramuscular injections in a volume equal to the dexamethasone administered to the rat with the same weight; group two (dexamethasone) were given 0.125 $\mathrm{mg} \mathrm{kg}$ dexamethasone sodium phosphate (Darou Pakhsh Pharma. Chem. Co., Tehran, Iran) daily by intramuscular injections; group three (dexamethasone+niacin) treated with $0.125 \mathrm{mg} \mathrm{kg}^{-1}$ dexamethasone daily by intramuscular injections along with $200 \mathrm{mg} \mathrm{kg}^{-1}$ niacin (Novin Kavosh Mamtir Co., Tehran, Iran) daily by oral gavages and group four (niacin) were given $200 \mathrm{mg} \mathrm{kg}^{-1}$ niacin daily by oral gavages. Dosages of dexamethasone and niacin were chosen according to the works accomplished by Bagdade et al. (1976) and Barboriak and Meade (1971), respectively).

Animals had free access to tap water and standard rat chow diet prepared by Razi Vaccine and Serum Research Institute, Shiraz, Iran. All animals were weighed daily during the experiment.

Procedures used in the present study are in accordance with institutional ethical guidelines of School of Veterinary Medicine, Shiraz University, for care and use of laboratory animals in experiments.

Serum leptin assays: At the end of the experimental period, after an over-night starvation, blood samples were collected from all animals under chloroform anesthesia by cardiac puncture. After centrifugation at $2000 \mathrm{rpm}$ for $20 \mathrm{~min}$, harvested sera were stored in $70^{\circ} \mathrm{C}$ until use. Serum leptin level was assayed by ELISA method using mouse/rat leptin kit (Mediagnost, Reutlingen, Germany).

Collection of inguinal adipose tissue and determination of ob gene mRNA expression: The quantity of inguinal fat leptin mRNA was determined by quantitative real-time PCR. After blood collection, animals were killed by deepening anesthesia. Inguinal fat samples were excised and immediately frozen in liquid nitrogen and kept in $-70^{\circ} \mathrm{C}$ until use. Total RNA was extracted from adipose tissue by using RNX-Plus commercial kit (CinnaGen Inc. Tehran, Iran) according to manufacturer's instructions. After DNase 
(Fermentas, Vilnius, Lithuania) treatment and normalization by spectrophotometric method, RNA was reverse transcribed and the cDNA obtained was used for PCR amplification to estimate the expression of leptin. $\beta$-Actin gene was used as the endogenous control gene. The primer sequences used were the following: (1) leptin: forward primer: 5'-ATC AAG ACC ATT GTC ACC AGG ATC-3', reverse primer: 5'-CTG GTC CAT CTT GGA CAA ACT CA-3' yielding a 129-bp size product; and (2) $\beta$-Actin: forward primer: 5'-GAA ATC GTG CGT GAC ATT AAG-3', reverse primer: 5'-GCT AGA AGC ATT TGC GGT GGA-3' yielding a 511-bp size product. The PCR thermocycling conditions for the genes were as follows: an initial denaturation for $5 \mathrm{~min}$ at $94{ }^{\circ} \mathrm{C}, 40$ cycles with denaturation at $94{ }^{\circ} \mathrm{C}$ for 30 seconds, primer annealing at $56 / 5{ }^{\circ} \mathrm{C}$ (leptin) and $54^{\circ} \mathrm{C}$ ( $\beta$-Actin) for 35 seconds and primer extension at $72{ }^{\circ} \mathrm{C}$ for 45 seconds and a final extension step at $72{ }^{\circ} \mathrm{C}$ for $5 \mathrm{~min}$. Nine microliters of each PCR product were subjected to $2 \%$ agarose gel electrophoresis containing ethidium bromide and visualized under ultraviolet light.

The quantitative RT-PCR was performed by a real time PCR kit (Bioneer, Seoul, South Korea) using SYBR Green in a Mini Opticon thermocycler (Bio-Rad laboratories Inc., California, USA). The results for leptin mRNA levels were presented relative to the expression of $\beta$-Actin.

Statistical analysis: Data were presented as mean \pm SD. Data analysis was carried out by using one-way ANOVA and Tukey's multiple comparison test as the post hoc (SPSS 11.5 for windows software). Differences were considered significant at $\mathrm{p}<0.05$.

\section{RESULTS}

Body weight: No significant difference observed in body weight of rats from different groups during the experiment (data not shown).

Serum leptin levels: Dexamethasone treatment (group two) increased serum leptin level more than 3.2 folds as compared to control group $(\mathrm{p}=0.001)$. Rats treated with dexamethasone+niacin (group three) had statistically higher leptin level than control group $(\mathrm{p}=$ 0.007). Although leptin level in these rats was $17.8 \%$ lower than group 2; however this decrease was not significant ( $>00.05$ ). Niacin administration (group four) had no effect on serum leptin concentration and niacin treated rats had statistically the same level of leptin as compared to control $(p>0.05)$ which was significantly lower than dexamethasone treated rats $(\mathrm{p}<0.001)$ (Fig. 1).

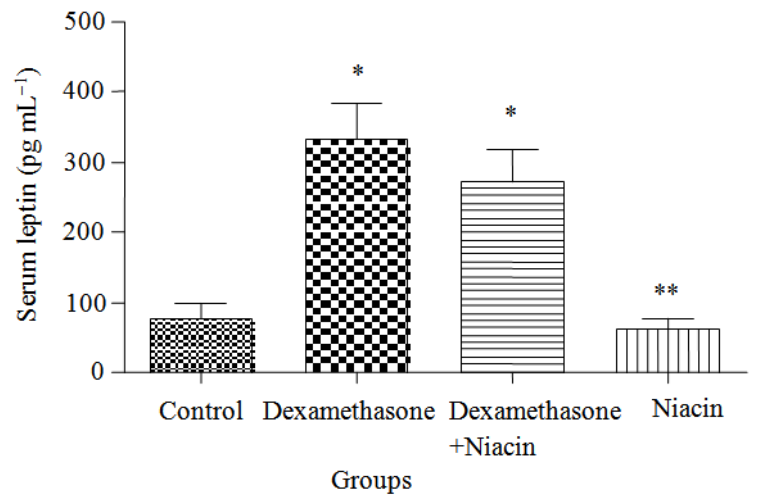

Fig. 1:Serum leptin levels presented as mean $\pm S D$ in control, dexamethasone, dexamethasone+niacin and niacin treated rats $(n=6$ each) at the end of the experiment. * and ** signs are used to demonstrate significant difference with control and dexamethasone treated groups respectively $(\mathrm{p}<0.05)$

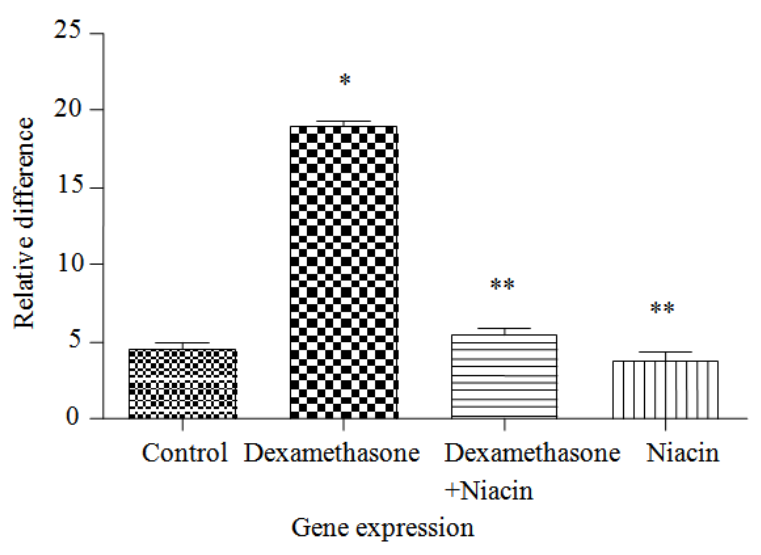

Fig. 2: $O b$ gene mRNA expression in inguinal adipose tissue presented as mean $\pm \mathrm{SD}$ in control, dexamethasone, dexamethasone+niacin and niacin treated rats $(n=6$ each) at the end of the experiment. $\beta$-Actin was used as the house keeping gene. * and ** signs are used to demonstrate significant difference with control and dexamethasone treated groups respectively $(\mathrm{p}<0.05)$

Ob gene mRNA levels in inguinal adipose tissue: The analysis of mRNA expression of leptin in inguinal adipose tissue showed that dexamethasone treatment has increased mRNA level of $o b$ gene 3.1 folds as compared to control $(\mathrm{p}<0.001)$. Interestingly, concomitant administration of niacin with dexamethasone decreased leptin gene mRNA expression more than $71 \%$ compared to dexamethasone 
treated rats $(p<0.001)$ and reversed it to the control level ( $p>0.05)$.

Rats treated with niacin alone, had statistically the same level of leptin gene expression in comparison with control group ( $>>0.05)$ (Fig. 2).

\section{DISCUSSION}

Leptin, the product of $o b$ gene, was originally discovered as an adipocyte-derived hormone involved in the central control of body weight and energy homeostasis (Zhao and $\mathrm{Wu}, 2005$ ). The proatherosclerotic effect of leptin has recently received a great deal of attention. Leptin stimulates vascular smooth muscle proliferation (Oda et al., 2001), accelerates vascular calcification (Parhami et al., 2001), induces oxidative stress in endothelial cells (Yamagishi et al., 2001) and promotes coagulation by increasing platelet adhesiveness (Konstantinides et al., 2001). These findings make it indispensable to investigate for agents with the ability to modulate serum leptin levels in hyperleptinemic conditions. While tissue fat adiposity along with gender, are the main determinants of leptin gene expression and release (Trayhurn et al., 1998); other factors or conditions may induce hyperleptinemia and increased expression of $o b$ gene independent of body weight. Zhao and $\mathrm{Wu}$ (2005) observed that high-cholesterol diet induces hyperleptinemia and elevates $o b$ gene mRNA expression in adipose tissue of rabbits, while body weights were not significantly different from control group. Mooradian et al. (2000) showed that monosaccharide-enriched diets cause hyperleptinemia in rats without affecting body weight. It has been clearly demonstrated that glucocorticoid administration could be associated with hyperleptinemia and increased $o b$ gene expression in vitro as well as in laboratory animals and humans Murakami et al., 1995; De Vos et al., 1995; Slieker et al., 1996; Reul et al., 1997; Papaspyrou-Rao et al., 1997; Bradley and Cheatham, 1999; Caldefie-Chezet et al., 2001; Lee et al., 2007; Jahng et al., 2008). Consistent with these reports, dexamethasone administration in our study, significantly increased serum leptin levels as well as $o b$ gene expression as compared to control. Besides, body weights of rats remained statistically the same among different groups.

Niacin is a drug which can affect adipocytes' metabolic pathways especially by inhibiting lipolysis and mobilization of free fatty acids (Kamanna and Kashyap, 2008; Balasubramanyam et al., 2006). Recently, Yang et al., reported that administration of $200 \mathrm{mg} \mathrm{kg}{ }^{-1}$ day $^{-1}$ niacin for six weeks could significantly reduce serum leptin levels as well as leptin mRNA expression in rabbits fed with high-cholesterol diet (Yang et al., 2008). This finding motivated us to evaluate the effect of niacin on hyperleptinemia and increased $o b$ gene expression due to dexamethasone administration. In our study, although niacin administration along with dexamethasone, significantly reduced leptin mRNA expression and reversed it to the control level, serum leptin concentrations in rats treated with dexamethasone+niacin only tended to decrease and the reduction was not significant as compared to dexamethasone treated animals. The insignificant change in serum leptin concentration despite of obvious reduction in $o b$ gene mRNA expression may be due to the short term of the study.

It is not possible to deduce the mechanism of action of niacin in reversing dexamethasone-induced $o b$ gene mRNA over-expression from the outcomes of the present study, however; it has been demonstrated that dexamethasone reduces Peroxisome ProliferatorActivated Receptor $\gamma$ (PPAR $\gamma$ ), a key transcription factor predominantly expressed in adipocytes, gene expression in primary porcine adipocytes (Zhang et al., 2008), as well as in 3T3-L1 adipocytes (She et al., 2007). In this regard, Reul et al. (1997) reported that the expression of PPAR $\gamma$ is inversely related to that of $o b$, where De Vos et al. (1995) observed that the $o b$ promoter is regulated by PPAR $\gamma$ and PPAR $\gamma$ activators such as thiazolidinediones reduce $o b$ gene expression in rodents through activation of PPAR $\gamma$. Conjugated linoleic acid, a natural ligand for PPAR $\gamma$, could also decrease the levels of leptin possibly via activating PPAR $\gamma$ (Zhou et al., 2004). So PPAR $\gamma$ may play a role in the regulation of leptin metabolism. Yang et al., observed that niacin up-regulates PPAR $\gamma$ mRNA expression in hypercholesterolemic rabbits (Yang et al., 2008). Although speculative, but niacin may reduce leptin mRNA expression through up-regulation of PPAR $\gamma$.

\section{CONCLUSION}

Conclusively, serum leptin tended to decrease while $o b$ gene over-expression in adipose tissue completely reversed due to niacin administration in dexamethasone treated rats. This study may pave the road for further investigations on plausible positive effects of niacin on leptin disturbances and its consequences in patients under glucocorticoid therapy.

\section{ACKNOWLEDGEMENT}

Funding for this study was provided by School of Veterinary Medicine, Shiraz University, Shiraz, Iran. 


\section{REFERENCES}

Bagdade, J.D., E. Yee, J. Albers and O.J. Pykalisto, 1976. Glucocorticoids and triglyceride transport: Effects on triglyceride secretion rates, lipoprotein lipase and plasma lipoproteins in the rat. Metabolism, 25: 533-542. DOI: 10.1016/00260495(76)90007-X

Balasubramanyam, A., R.V. Sekhar, F. Jahoor, H.J. Pownall and D. Lewis, 2006. Pathophysiology of adipocyte defects and dyslipidemia in HIV lipodystrophy: New evidence from metabolic and molecular studies. Am. J. Infect. Dis., 2: 167-172. DOI: 10.3844/ajidsp.2006.167.172

Barboriak, J.J. and R.C. Meade, 1971. Nicotinic acid and alcohol-induced lipemia. Atherosclerosis, 13: 199-203. DOI: 10.1016/0021-9150(71)90022-0

Bradley, R.L. and B. Cheatham, 1999. Regulation of $o b$ gene expression and leptin secretion by insulin and dexamethasone in rat adipocytes. Diabetes, 48: 272-278. DOI: 10.2337/diabetes.48.2.272

Bubanovic, I., S. Kojic, S. Najman and Z. Andjelkovic, 2005. Immunomodulatory treatment of infertility in men with elevated antisperm antibodies. Am. J. Immunol., $\quad 1$ : 130-134. DOI: 10.3844/ajisp.2005.130.134

Caldefie-Chezet, F., C. Moinard, R. Minet-Quinard, F. Gachon and L. Cynober et al., 2001. Dexamethasone treatment induces long-lasting hyperleptinemia and anorexia in old rats. Metabolism, 50: 1054-1058. DOI: 10.1053/meta.2001.25803

Crouse, J.R., 1996. New developments in the use of niacin for treatment of hyperlipidemia: New considerations in the use of an old drug. Coron. Artery Dis., 7: 321-326. PMID: 8853585

De Vos, P., R. Saladin, J. Auwerx and B. Staels, 1995. Induction of ob gene expression by corticosteroids is accompanied by body weight loss and reduced food intake. J. Biol. Chem., 270: 15958-15961. PMID: 7608151

Friedman, J.M., 2002. The function of leptin in nutrition, weight and physiology. Nutr. Rev., 60: S1-S14. DOI: 10.1301/002966402320634878

Jahng, J.W., N.Y. Kim, V. Ryu, S.B. Yoo and B.T. Kim et al., 2008. Dexamethasone reduces food intake, weight gain and the hypothalamic 5-HT concentration and increases plasma leptin in rats. Eur. J. Pharmacol., 581: 64-70. DOI: 10.1016/j.ejphar.2007.11.029

Kamanna, V.S. and M.L. Kashyap, 2008. Mechanism of action of niacin. Am. J. Cardiol., 101: 20B-26B. DOI: 10.1016/j.amjcard.2008.02.029
Khalsa, J.H., F. Vocci and A. Dobs, 2006. Hormonal and metabolic disorders of human immunodeficiency virus infection and substance abuse. Am. J. Infectious Dis., 2: 125-129. DOI: 10.3844/ajidsp.2006.125.129

Konstantinides, S., K. Schafer, S. Koschnick and D.J. Loskutoff, 2001. Leptin-dependent platelet aggregation and arterial thrombosis suggests a mechanism for atherothrombotic disease in obesity. J. Clin. Investigation, 108: 1533-1540. DOI: 10.1172/JCI200113143

Lee, M.J., Y. Wang, M.R. Ricci, S. Sullivan and C.D. Russell et al., 2007. Acute and chronic regulation of leptin synthesis, storage and secretion by insulin and dexamethasone in human adipose tissue. Am. J. Phys., Endocrinol. Metabolism, 292: 858-864. DOI: 10.1152/ajpendo.00439.2006

Mooradian, A.D., J. Chehade, R. Hurd and M.J. Haas, 2000. Monosaccharide-enriched diets cause hyperleptinemia without hypophagia. Nutrition, 16: 439-441. DOI: 10.1016/S0899-9007(00)00229-X

Murakami, T., M. Iida and K. Shima, 1995. Dexamethasone regulates obese expression in isolated rat adipocytes. Biochem. Biophy. Res. Commun., 214: 1260-1267. PMID: 7575539

Oda, A., T. Taniuchi and M. Yokoyama, 2001. Leptin stimulates rat aortic smooth muscle cell proliferation and migration. Kobe J. Med. Sci., 47: 141-150. PMID: 11729375

Papaspyrou-Rao, S., S.H. Schneider, R.N. Perersen and S.K. Fried, 1997. Dexamethasone increases leptin expression in humans in vivo. J. Clin. Endocrinol. Metab., 82: 1635-1637. PMID: 9141563

Parhami, F., Y. Tintut, A. Ballard, A.M. Fogelman and L.L. Demer, 2001. Leptin enhances the calcification of vascular cells: Artery wall as a target of leptin. Circulation Res., 88: 954-960. DOI: 10.1161/hh0901.090975

Patel, R., M. Patel, R. Tsai, V. Lin and A.L. Bookout et al., 2011. LXR $\beta$ is required for glucocorticoidinduced hyperglycemia and hepatosteatosis in mice. J. Clin. Investigation, 121: 431-441. DOI: 10.1172/JCI41681

Ren, J., 2004. Leptin and hyperleptinemia-from friend to foe for cardiovascular function. J. Endocrinol., 181: 1-10. DOI: 10.1677/joe.0.1810001

Reul, B.A., L.N. Ongemba, A.M. Pottier, J.C. Henquin and S.M. Brichard, 1997. Insulin and insulin-like growth factor 1 antagonize the stimulation of ob gene expression by dexamethasone in cultured rat adipose tissue. Biochem. J., 324: 605-610. PMID: 9182724 
Sakr, H.F., 2010. Endothelial dysfunction induced by type 2 diabetes mellitus and fibrinolytic activity. Am. J. Biochem. Biotech., 6: 103-110. DOI: 10.3844/aibbsp.2010.103.110

She, Q.M., J. Zhao, X.L. Wang, C.M. Zhou and X.Z. Shi, 2007. Effect of dexamethasone on peroxisome proliferator activated receptor-gamma mRNA expression in 3T3-L1 adipocytes with the human recombinant adiponectin. Chin. Med. J., 120: 155158. PMID: 17335662

Singhal, A., I.S. Farooqi, T.J. Cole, S. O'Rahilly and M. Fewtrell et al., 2002. Influence of leptin on arterial distensibility: A novel link between obesity and cardiovascular disease? Circulation, 106: 1919-1924.

DOI: 10.1161/01.CIR.0000033219.24717.52

Slieker, L.J., K.W. Sloop, P.L. Surface, A. Kriauciunas and F. LaQuier et al., 1996. Regulation of expression of ob mRNA and protein by glucocorticoids and cAMP. J. Biol. Chem., 271: 5301-5404. DOI: 10.1074/jbc.271.10.5301

Taylor, A.J., L.E. Sullenberger, H.J. Lee, J.K. Lee and K.A. Grace, 2004. Arterial biology for the investigation of the treatment effects of reducing cholesterol (ARBITER) 2: A double-blind, placebo-controlled study of extended-release niacin on atherosclerosis progression in secondary prevention patients treated with statins. Circulation, 110: 3512-3517. DOI: 10.1161/01.CIR.0000148955.19792.8D

Trayhurn, P., J.S. Duncan, N. Hoggard and D.V. Rayner, 1998. Regulation of leptin production: A dominant role for the sympathetic nervous system? Proc. Nutrit. Soc., 57: 413-419. DOI: 10.1079/PNS19980060
Wang-Fisher, Y.L., J. Han and W. Guo, 2002. Acipimox stimulates leptin production from isolated rat adipocytes. J. Endocrinol., 174: 267272. PMID: 12176665

Westphal, S., K. Borucki, E. Taneva, R. Makarova and C. Luley. 2007. Extended-release niacin raises adiponectin and leptin. Atherosclerosis, 193: 361365. DOI: 10.1016/j.atherosclerosis.2006.06.028

Yamagishi, S.I., D. Edelstein, X.L. Du, Y. Kaneda, M. Guzman and M. Brownlee, 2001. Leptin induces mitochondrial superoxide production and monocyte chemoattractant protein-1 expression in aortic endothelial cells by increasing fatty acid oxidation via protein kinase A. J. Biol. Chem., 276: 25096-25100. DOI: 10.1074/jbc.M007383200

Yang, J., S.P. Zhao, J. Li and S.Z. Dong, 2008. Effect of niacin on adipocyte leptin in hypercholesterolemic rabbits. Cardiovascular Pathol., 17: 219-225. DOI: 10.1016/j.carpath.2007.09.005

Zhang, H., J. Wu, B. Wang, Z. Lü and G. Yang, 2008. Regulation of SOCS-3, OB, GLUT4 and PPARgamma gene expression by insulin and dexamethasone in porcine primary adipocyte. Sheng Wu Gong Cheng Xue Bao, 24: 1354-1360. PMID: 18998535

Zhao, S.P. and Z.H. Wu, 2005. Atorvastatin reduces serum leptin concentration in hypercholesterolemic rabbits. Clin. Chim. Acta, 360: 133-140. DOI: 10.1016/j.cccn.2005.04.021

Zhou, X., C. Sun, L. Jiang and H. Wang, 2004. Effect of conjugated linoleic acid on PPAR gamma gene expression and serum leptin in obese rat. Wei Sheng Yan Jiu, 339: 307-309. PMID: 15211799 